\title{
Genome-wide Screens to Identify Genes of Human Pathogenic Yersinia Species that are Expressed during Host Infection
}

\author{
Andrew J. Darwin \\ Department of Microbiology, New York University School \\ of Medicine, New York, NY 10016
}

\begin{abstract}
An obvious goal in the study of bacteria that cause human disease is to identify the bacterial genes required for growth within the host. Historically, this has presented a significant technological challenge. However, with this goal in mind, the in vivo expression technology (IVET) and signature-tagged mutagenesis (STM) techniques were developed during the 1990s. These techniques have been used to identify virulence genes in the three human pathogenic Yersinia species, Y. enterocolitica, Y. pseudotuberculosis and $Y$. pestis, using variations of their mouse models of infection. In this review, each of these studies is described individually, including the pertinent details of how each was done, and a brief discussion of the genes identified. In addition, the results of these IVET and STM screens are compared, and the striking lack of overlap between the genes identified is discussed. Most of these studies were only recently published, which means that there have been few follow-up studies on some of the novel virulence genes identified. However, the $Y$. enterocolitica hreP, rscR and psp genes have become the subject of further studies, which are also summarized here. Finally, I briefly describe the use of the genome-wide (but not in vivo) technology, subtractive hybridization, to identify Yersinia virulence genes.
\end{abstract}

\section{Introduction}

This review is devoted to the use of "genome-wide" approaches to identify Yersinia virulence genes, with an emphasis on those technologies that can be directly applied during host infection. A number of these in vivo technologies are available. However, it is not the purpose of this review to go into the technical details of each available technique. For a comprehensive review of the available in vivo strategies, I refer the reader elsewhere (Handfield and Levesque, 1999).

In Yersinia spp, two such in vivo technologies have been used on multiple occasions, and these studies will be covered in detail. The first was in vivo expression technology (IVET), which was developed in John Mekalanos' laboratory (Mahan et al., 1993). The second was signature-tagged transposon mutagenesis (STM), developed in David Holden's laboratory (Hensel et al., 1995). In a few cases, some of the genes identified in

For correspondence: Department of Microbiology MSB 228, New York University School of Medicine, 550 First Avenue, New York, NY 10016

Phone: (212) 263-3223; Fax: (212) 263-8276; E-mail: darwia01@med.nyu.edu these screens have become the subjects of subsequent studies, which will also be summarized in this review.

I have listed most of the genes found in a separate table for each screen. In several cases, the authors of the original studies reported that analysis of some of the DNA sequence information revealed no similarity to the databases. I have decided to omit these from the tables, simply because it is not informative in the context of this review. Of course, this does not mean that I think these potentially novel genes are not interesting.

\section{IVET screens}

IVET identifies bacterial genes that are expressed during an animal infection, but not during selected laboratory growth conditions. The hypothesis is that genes that meet these criteria are likely to be required for virulence, but unlikely to be so-called housekeeping genes. However, IVET does not directly reveal whether or not the genes identified are required for virulence. For this, a null mutant must be constructed and its phenotype determined. This has been done for only a small minority of the genes identified by IVET, in a number of different bacterial species. In the case of the human pathogenic Yersinia spp., IVET has been used to study Y. enterocolitica only, in both intestinal and systemic mouse models of infection (Young and Miller, 1997; Gort and Miller, 2000). This review focuses on the human-pathogenic Yersinia spp. However, it is also worthy to note that IVET has also recently been used to study the fish pathogen Y. ruckeri (Fernandez et al., 2004).

IVET identification of genes expressed early in infection The first $Y$. enterocolitica IVET screen studied a derivative of strain 8081 (biotype 1B, serotype O8). The screen identified genes expressed in murine Peyer's patch tissue throughout at least the first 46 hours after an orogastric infection (Young and Miller, 1997). A library of strains with random chromosomal cat operon fusions (encoding chloramphenicol acetyltransferase) was constructed. The source of genomic DNA for this library was a strain lacking the virulence plasmid (pYV). Whilst this was understandably done to avoid the reidentification of known pYV virulence genes, in future studies it might also be interesting to know which pYV genes would meet the subsequent selection criteria.

The cat operon fusion library was used to infect BALB/c mice. Chloramphenicol was administered to the animals throughout the first 46 hours of infection. This enriched for those strains with cat fusions expressed during infection. Strains that survived two rounds of this enrichment were recovered from the Peyer's patches and further characterized to identify cat fusions that were not expressed on rich or minimal agar plates in the laboratory at $26^{\circ} \mathrm{C}$. This class of strains was designated to contain cat fusions to host responsive elements (hre). 61 different 
hre allelic groups were identified, and the DNA sequence of 48 was determined in the original report (Table 1; Young and Miller, 1997).

Following the original publication, the DNA sequence of the remaining 13 was determined, and the information has been incorporated into Table 1 (G.M. Young and V. L. Miller, personal communication). In addition, some of the fusions that originally revealed no homology to the databases were analyzed further (Heusipp et al., 2003). One is a fusion to a homologue of the $E$. coli nadB gene
(Table 1). Another is a fusion to a region with similarity to the $E$. coli rpoE promoter. Further sequence analysis confirmed that this is a fusion to the $Y$. enterocolitica rpoE promoter. Interestingly, attempts to construct a $Y$. enterocolitica rpoE null mutant have been unsuccessful (Heusipp et al., 2003). This indicates that rpoE is an essential gene in Y. enterocolitica, as is the case in E. coli (De Las Penas et al., 1997).

The authors of this IVET study divided the hre loci into functional groups (stress response, iron acquisition,

\begin{tabular}{|c|c|c|}
\hline Encoded protein/homologue a & Predicted function/property & Role in virulence ${ }^{b}$ \\
\hline \multicolumn{3}{|l|}{ Stress response } \\
\hline $70 \%$ Gsh, E. coli & Glutathione synthesis & ND \\
\hline 91\% YdhD, E. coli & Glutaredoxin & ND \\
\hline $56 \%$ MtpS, Providencia stuartii & DNA methylase & ND \\
\hline $69 \%$ MutL, E. coli & Methylation-dependent DNA repair & ND \\
\hline $79 \% \mathrm{HfIX}$, E. coli & GTP-binding protein & ND \\
\hline $67 \%$ RecB, E. coli & Exodeoxyribonuclease $\mathrm{V}$ & ND \\
\hline $61 \%$ AcrR, E. coli & Stress response regulator & ND \\
\hline Similarity to $E$. coli rpoE promoter & Extracytoplasmic stress response sigma factor & Essential gene \\
\hline $100 \%$ ClpX, Y. enterocolitica & ATP-binding subunit of Clp protease & ND \\
\hline \multicolumn{3}{|l|}{ Iron aquisition } \\
\hline 100\% Irp2, Y. enterocolitica & HMWP2, Iron acquisition & \\
\hline 100\% Irp3, Y. enterocolitica & Unknown function (probable iron acquisition role) & Yes \\
\hline $85 \%$ FoxA, Y. enterocolitica & Siderophore receptor & ND \\
\hline $100 \%$ FyuA, Y. enterocolitica & Yersiniabactin receptor & Yes \\
\hline $85 \%$ YfuB, Y. enterocolitica & Iron transport & ND \\
\hline $59 \%$ HemD, E. coli & Uroporphrynigen III synthase & ND \\
\hline \multicolumn{3}{|l|}{ Cell envelope maintenance } \\
\hline 74\% MdoG, E. coli & Membrane-derived oligosaccharide synthesis & ND \\
\hline 79\% MdoH, E. coli & Membrane-derived oligosaccharide synthesis & Yes \\
\hline $66 \%$ LpxA, Y. enterocolitica & Acyl-transferase & Yes \\
\hline \multicolumn{3}{|l|}{ Miscellaneous } \\
\hline 99\% Tnp, E. coli & Transposase & ND \\
\hline $65 \%$ AceB, E. coli & Malate synthase & ND \\
\hline $59 \%$ CpdP, Vibrio fisheri & 3'-5' cAMP phosphodiesterase & ND \\
\hline $31 \%$ HoxQ, E. coli & Nickel transport/Hydrogenase activity & ND \\
\hline $88 \%$ Tgt, E. coli & tRNA-guanine transglycosylase & ND \\
\hline $100 \%$ RscR, Y. enterocolitica & Transcriptional regulator & Yes \\
\hline $56 \%$ Kpyl, E. coli & Pyruvate kinase & ND \\
\hline $100 \%$ HreP, Y. enterocolitica & Protease & Yes \\
\hline $80 \%$ NadB, E. coli & quinolinate synthetase, B protein & ND \\
\hline 92\% QueA, E. coli & synthesis of queuine in tRNA & ND \\
\hline $54 \%$ MioC, E. coli & Unknown function & ND \\
\hline $81 \%$ YrbA, E. coli & Unknown function & ND \\
\hline $46 \%$ Rub, Desulfovibrio vulgaris & Unknown function & ND \\
\hline $32 \%$ Orf, E. coli (Accession U73857) & Unknown function & ND \\
\hline \multicolumn{3}{|c|}{$\begin{array}{l}\text { a. The closest homologous protein is shown, along with the percent amino acid identity. Some fusion sequences revealed no similarity to the data- } \\
\text { bases, and they are omitted from this table. } \\
\text { b. Indicates whether a null mutation affects } Y \text {. enterocolitica virulence (as measured by altered } \mathrm{LD}_{50} \text { or kinetics of infection). } \\
\text { ND = not determined. }\end{array}$} \\
\hline
\end{tabular}


cell envelope maintenance and miscellaneous functions; Table 1). Some of the hre loci were known or suspected to be required for normal virulence. These include the iron acquisition proteins HMWP2 and FyuA, which are part of the high pathogenicity island (Carniel, 2001; Lesic and Carniel, 2004). However, the majority of the hre loci had not previously been implicated in virulence. Therefore, as part of their study, Young and Miller went on to show that null mutations in four of these novel genes $(m d o H, I p x A$, hreP and $r s c R$ ) affected the course of a mouse infection. In addition, the $r s c R$ and $h r e P$ genes became the subjects of more extensive studies, which are described below.

$\mathrm{MdoH}$ homologue. One of the genes studied further, originally designated as hre-13, is a homologue of $E$. coli $m d o H$. This gene is predicted to encode a protein involved in the synthesis of cyclic $\beta$-glucans (membrane derived oligosaccharides). These molecules are essential for virulence of the plant pathogen Pseudomonas syringae pv. syringae (Mukhopadhyay et al., 1988), and also affect bacterial survival in environments of low osmotic strength (Kennedy, 1996). The hre-13 null mutant was slightly delayed in the ability to colonize the Peyer's patches and mesenteric lymph nodes early in infection (Young and Miller, 1997). However, the $L D_{50}$ dose after oral infection was unchanged. This phenotype is consistent with a role early in the infectious process, as would be expected for genes identified in this screen.

LpxA homologue. Another gene that was studied further is also predicted to be involved in cell envelope biosynthesis. The gene, originally designated hre-14, encodes a homologue of the acyl-transferase LpxA, which is required for lipid A synthesis (Galloway and Raetz, 1990; Vuorio et al., 1991; Kelley et al., 1993; Vuorio et al., 1994). The hre-14 null mutant was delayed in its ability to colonize the Peyer's patches and mesenteric lymph nodes, and this phenotype appeared to be more severe than that of the $\mathrm{mdoH}$ homologue mutant (Young and Miller, 1997). Furthermore, the hre-14 null mutant had a slight increase in oral $L_{50}$ dose (a little over 5 times that of the wild type) and the average day of death increased by approximately $25 \%$. These phenotypes are consistent with a role throughout the course of infection.

HreP. A hreP null mutant (originally designated hre-22) has a 33-fold increase in $L D_{50}$ following oral infection of BALB/c mice (Young and Miller, 1997). The predicted HreP protein is most similar to the cyanobacterial calcium-stimulated protease PrcA of Anabena variabilis. In addition, it was noted that HreP had significant similarity to several subtilisin-like proteases, which belong to the family of eukaryotic subtilisin/kexin-like proprotein convertases (Heusipp et al., 2001). These proteases are initially synthesized as a single protein, consisting of the $\mathrm{N}$-terminal proprotein and the $\mathrm{C}$-terminal mature protease. Consistent with this, it was shown that a HreP$6 \times$ His fusion protein undergoes a single autocatalytic cleavage event (Heusipp et al., 2001). The amino acid sequence of the cleavage site matched the consensus for the subtilisin/kexin-like proprotein convertases. However, the ability of HreP to cleave other proteins could not be demonstrated. The authors offered some possible explanations for this, including lack of knowledge about the optimal conditions for enzyme activity, or substrate specificity, and inhibitory effects of the proprotein, which could not be purified away from the mature protease. The identification of the normal substrate for HreP holds the promise of revealing insight into its physiological function. However, this will not be trivial, especially if the substrate is a host protein. Unfortunately, conditions for hreP gene expression from its native promoter in the laboratory have not yet been determined. This has prevented some important studies, such as examining the subcellular location of this protease.

It is also interesting to note that hreP is located in a cluster of flagellar biosynthesis and chemotaxis genes (Heusipp et al., 2001). These flanking genes are organized differently in enteric species. This suggests that $Y$. enterocolitica may have acquired hreP by horizontal transfer. The gene is also closely linked to inv, encoding the Invasin protein required for entry into host cells.

RscR. A polar $r s c R$ null mutant (originally called hre$20)$ was shown to have interesting in vivo phenotypes. There was a modest five-fold increase in $L D_{50}$ following oral infection of BALB/c mice. However, when the bacterial load was monitored over time, the mutant was consistently found to be present in increased numbers in the liver and spleen when compared to wild type (Young and Miller, 1997). This kinetic phenotype was reproduced with a non-polar rscR in frame deletion mutant (Nelson et al., 2001). Therefore, the gene designation $r s c R$ was chosen to indicate the effect of having the wild type gene intact (reduced splenic colonization).

$\mathrm{RscR}$ is predicted to be a member of the LysR family of transcriptional regulators, most closely related to the uncharacterized hypothetical YeiE protein of E. coli K12 (68\% identity). It was hypothesized that the $r s c R$ null mutant phenotype was probably due to altered expression of one or more RscR-regulated genes, which prompted a transposon-based screen to identify them (Nelson et al., 2001). This led to the identification of the rscBAC locus, which is homologous to the $h m w A B C$ operon of Haemophilus influenzae (although the gene order is different). In the transposon screen, various $r s c B:: / a c Z$ insertion mutants were isolated, and analysis of them indicated that $r s c B:: / a c Z$ expression was induced 5 to 40 fold when RscR was overproduced.

The similarity to the $H$. influenzae operon suggested that RscA is an extracellular adhesin, which may rely on RscB and RscC for its processing and secretion. Therefore, an $r s c A$ null mutant was constructed and analyzed (Nelson et al., 2001). The rscA null mutant had a similar kinetic phenotype in mice to that of the $r s c R$ null mutant (increased dissemination to the spleen, but normal colonization of the Peyer's patches and mesenteric lymph nodes). Although the authors conceded that their evidence was indirect, they came to the reasonable conclusion that $\mathrm{RscR}$ regulates the $r s c B A C$ locus during host infection.

It is intriguing that $r s c R$ or $r s c A$ null mutations cause increased systemic spread, but do not decrease the LD $_{50}$ (in fact, it may be slightly increased; Young and Miller, 1997). Further study will be required to determine the role 
of the putative RscA adhesin in the pathogenesis of a $Y$. enterocolitica infection.

\section{IVET identification of genes expressed during systemic infection}

The second $Y$. enterocolitica IVET screen studied the same strain as the first (a derivative of strain 8081, which is biotype $1 \mathrm{~B}$, serotype 08 ). This screen identified genes expressed in murine spleen throughout at least the first 24 hours after an intraperitoneal infection (Gort and Miller, 2000). The same chromosomal cat operon fusion library from the first IVET screen was used. Once again, chloramphenicol was administered to the animals to enrich for those strains with cat fusions expressed during infection. Strains that survived two rounds of this enrichment were recovered from the spleen and further characterized to identify host responsive elements, exactly as described for the first IVET screen. In this case the host responsive elements identified were designated as sif (systemic infection factor). 31 different sif allelic groups were identified, and the DNA from at least one representative of each group was determined (Table 2). Subsequently, in vivo expression of some of the sif genes was confirmed by chloramphenicol-mediated enrichment of the $\Phi$ (sif-cat) fusion strain when it was used to infect a mouse in competition with the wild type strain (Gort and Miller, 2000).

The sif genes apparently encode proteins that play roles in general physiology, transcriptional regulation, and various other functions. Some of the genes were already known to play a role in virulence (fyuA and $\operatorname{man} B$ ), or strongly suspected to do so (the IffG homologue). However, once again the majority of the genes identified had not previously been shown to play a role in virulence. The authors constructed a null mutation in one of these genes, originally designated as sif15 (see below; Gort and Miller, 2000).

There was little overlap between the genes identified in the two Y. enterocolitica IVET screens (compare Tables 1 and 2). In fact, the only gene identified in both screens was fyuA, which is part of the high pathogenicity island. The lack of overlap may indicate that different genes are expressed during early (intestinal) and late (systemic) stages of infection. It strongly suggests that there is much to be gained by doing IVET screens at different stages of infection, in different tissues, and following different modes of infection. The subject of overlap between the various IVET and STM screens will be discussed in more detail later.

Sif15. The predicted Sif15 protein is $69 \%$ identical to a putative outer membrane protein in various Salmonella enterica serovars, and 20\% identical to HP0694 of Helicobacter pylori. Following a mixed intraperitoneal infection with the wild type, a sif15 null mutant had a competitive defect in the spleen (competitive index of 0.08; see Gort and Miller, 2000). However, following orogastric infection the mutant had a significantly less severe competitive defect in the Peyer's patches (competitive index of 0.27; Gort and Miller, 2000). The authors concluded that Sif15 plays an important role during systemic infection, but is less important during colonization of the Peyer's patch tissue. A role for Sif15 during systemic infection might be expected to increase the $\mathrm{LD}_{50}$, but this has not yet been tested. In the laboratory, sif15 expression was shown to be higher at $37^{\circ} \mathrm{C}$ than at $26^{\circ} \mathrm{C}$, consistent with a role in the host.

\section{STM screens}

STM solves the ethical, financial and labor-related concerns associated with screening large numbers of null

\begin{tabular}{|l|l|l|}
\hline \multicolumn{2}{|l|}{ Table 2. IVET identification of Y. enterocolitica genes (sif) expressed in spleen during systemic infection. } \\
\hline Encoded protein/homologue ${ }^{\text {a }}$ & Predicted function/property & Role in virulence ${ }^{\text {b }}$ \\
\hline $37 \%$ SitC, Staphylococcus epidermidis & ABC transporter component & ND \\
\hline $80 \%$ LepA, E. coli & Membrane-bound GTPase & ND \\
\hline $76 \%$ RffG, Erwinia carotovora & LPS biosynthesis & ND \\
\hline $84 \%$ FrdA, Proteus vulgaris & Fumarate reductase & ND \\
\hline $80 \%$ MetL, E. coli & Aspartokinase/homoserine reductase & ND \\
\hline $91 \%$ Yohl, E. coli & Putative transcriptional regulator & ND \\
\hline $82 \%$ BioH, E. coli & Biotin synthesis & ND \\
\hline $100 \%$ FyuA, Y. enterocolitica & Yersiniabactin receptor & Yes \\
\hline $100 \%$ ManB, Y. enterocolitica & O-antigen biosynthesis & Yes \\
\hline $78 \%$ YicD, E. coli & Unknown function & ND \\
\hline $70 \%$ YifJ, Bacillus subtilis & Pyruvate-flavodoxin oxidoreductase & ND \\
\hline $68 \%$ RhIB, E. coli & RNA helicase & ND \\
\hline $69 \%$ Orf Salmonella & Putative outer membrane protein & Yes \\
\hline (20\% HP0694 Helicobacter pylori) & & \\
\hline $32 \%$ GacA P. syringae & Transcriptional regulator & ND \\
\hline $\begin{array}{l}\text { a. The closest homologous protein is shown, along with the percent amino acid identity. Some fusion sequences revealed no similarity to the data- } \\
\text { bases, and they are omitted from this table. } \\
\text { b. Indicates whether a null mutation affects } \text { Y. enterocolitica virulence (as measured by altered LD } \\
\text { ND }=\text { not determined. }\end{array}$ & & \\
\hline
\end{tabular}


mutants for decreased virulence in an animal model of infection (Hensel et al., 1995). This is because STM allows relatively large groups of transposon-insertion mutants (e.g. 96 different mutants) to be screened in a single animal. STM will not identify essential genes because the mutants must be able to grow in the laboratory. Furthermore, mutants that can be complemented by wild type bacteria may not be identified in the mixed infections. The major advantage of STM is that it is a direct screen for decreased virulence of null mutants. It can identify mutants with either severe or subtle virulence defects, as demonstrated by the screens done with Yersinia spp. STM has been used in Y. enterocolitica (Darwin and Miller, 1999), Y. pseudotuberculosis (Karlyshev et al., 2001; Mecsas et al., 2001) and Y. pestis (Flashner et al., 2004). Together, these studies also covered several different routes of infection (oral, intraperitoneal, intravenous and subcutaneous).

Y. enterocolitica STM screen (intraperitoneal infection) The first Yersinia STM screen was done with $Y$. enterocolitica, using the same strain 8081 derivative as the IVET screens described above (Darwin and Miller, 1999). In this study, attempts to use an oral route of infection were unsuccessful. This was apparently due to the socalled "bottleneck" problem, which has been reported by a number of investigators using STM to study enteric pathogens (Mecsas, 2002). In the case of Y. enterocolitica, it appears that as few as 30 bacteria seed the Peyer's patches following an oral infection. Therefore, it was not possible to use a pool containing 96 different mutants in oral infections, even at a very high dose (Darwin and Miller, 1999). The effect of lowering the complexity of the pool (i.e. the number of different mutants) was not studied. However, an intraperitoneal (i.p.) route of infection, with pools of 96 mutants, was successful when a high dose was used (approximately $10^{4}$ times greater than the $L_{50}$ dose for a $Y$. enterocolitica i.p. infection).

The $Y$. enterocolitica signature-tagged transposon insertion mutants were initially isolated on minimal agar so that auxotrophs would not be present. These mutants were assembled into pools of 96 and used to infect mice by i.p. injection. Surviving bacteria were isolated from the spleen after 48 hours. Putative attenuated mutants identified from this first screen were then reassembled into new pools and screened a second time. After this doublescreening procedure, attenuation was confirmed for $81 \%$ of the strains identified. This was done by detecting a defect in the ability of the mutant to compete with the wild type, when mice were infected with an equal mixture of the two strains (i.p. infection, bacteria recovered from the spleen). A total of 2015 random transposon insertion mutants were screened, and 55 attenuated mutants were identified. Subsequent DNA sequence analysis indicated that 27 different virulence loci had been identified (Table 3). Of these, nine were encoded on the virulence plasmid, and 18 on the chromosome.

Most of the virulence plasmid genes that were identified encode components of the Ysc type III secretion apparatus, or are involved in the regulation of its production. Surprisingly, the screen identified only one of the yop genes, which encode the effector proteins secreted by the Ysc type III system (yopP, which is known as yopJ in Y. pestis and Y. pseudotuberculosis). The yopP null mutant had only a relatively subtle virulence defect (Table 3). YopP/J has been studied extensively using in vitro models, where it has been shown to play a role in inducing host cell apoptosis (reviewed by Orth, 2002). The reason(s) why more yop genes were not identified in the screen is unknown. One intriguing possibility is that some yop mutations can be complemented by a corresponding yop ${ }^{+}$strain during the mixed infections. However, this has not been tested experimentally. A less interesting, but perhaps more likely possibility is that the transposon did not insert randomly in the virulence plasmid. The failure to identify yop mutants is a common theme for all of the Yersinia STM studies (see below).

Nine of the 18 chromosomal virulence loci are in a single locus that is involved in biosynthesis of the O-antigen component of lipopolysaccharide (Table 3). All of these mutants had significant virulence defects as measured by the competition assay following intraperitoneal infection. This is consistent with the observation that a spontaneous $Y$. enterocolitica O-antigen mutant has a significantly increased $L D_{50}$ dose when administered by the oral route of infection (Zhang et al., 1997). Furthermore, the Oantigen is known to be important for a number of enteric pathogens, and O-antigen mutants had previously been isolated in STM screens of $S$. typhimurium and Vibrio cholerae (Hensel et al., 1995; Chiang and Mekalanos, 1998). Y. pseudotuberculosis O-antigen mutants were also isolated in a subsequent STM screen (see below).

The remaining nine chromosomal loci are predicted to be involved in a variety of functions (Table 3 ). These include the biosynthesis of cell envelope components (yifH and $n / p D)$, phosphate (pstC) and iron (irp1) acquisition, and stress response (dnaJ). Two independent mutants had transposon insertions in a homologue of the $E$. coli yibP gene. This gene has no known function, but may be co-transcribed with an upstream gene encoding a putative 2,3-diphosphoglycerate-independent phosphoglyceromutase. These two genes are conserved in the same order in Pseudomonas syringae pv. tomato, in which a transposon insertion in the upstream gene causes attenuation in a tomato plant infection (Morris et al., 1995). It is interesting that mutations in homologous loci, which might be involved in carbon metabolism, cause attenuation in both animal and plant models of infection, without affecting growth in vitro. It is also interesting to note that the E. coli YibP protein is approximately $40 \%$ identical to the C-terminal domain of NIpD, also identified in the STM screen.

When the $Y$. enterocolitica STM screen was originally published, one of the chromosomal loci was found to have no significant homology to database entries (Darwin and Miller, 1999). However, with the completion of the Y. enterocolitica genome sequence, I have re-examined the site of this transposon insertion. It is now clear that the transposon is inserted into the $Y$. enterocolitica $y s p C$ gene, which encodes one of the secreted effectors of the recently discovered Ysa type III secretion system (Foultier et al., 2003). The yspC null mutant had the most subtle virulence defect of all of the mutants isolated in the screen. However, this is consistent with the subtle 


\begin{tabular}{|c|c|c|}
\hline Encoded protein/homologue & Function or property & Competitive index ${ }^{b}$ \\
\hline \multicolumn{3}{|l|}{ Virulence plasmid } \\
\hline$y s c U(100 \%, Y e)$ & Ysc-Yop Type III secretion & 0.00025 \\
\hline $\operatorname{IcrV}(100 \%, \mathrm{Ye})$ & Ysc-Yop Type III secretion & 0.000079 \\
\hline$y s c R(100 \%, Y e)$ & Ysc-Yop Type III secretion & 0.0043 \\
\hline yscC $(100 \%, Y e)$ & Ysc-Yop Type III secretion & 0.00071 \\
\hline yscL $(100 \%, Y e)$ & Ysc-Yop Type III secretion & 0.00053 \\
\hline $\operatorname{virF}(100 \%, Y e)$ & Yop regulon transcriptional activator & 0.00011 \\
\hline virG $(100 \%, Y e)$ & Ysc-Yop Type III secretion & ND \\
\hline уорР $(100 \%$, Ye $)$ & Yop effector protein & 0.17 \\
\hline sycT-уорм $(100 \%$, Ye $)$ & Intergenic region & 0.000031 \\
\hline \multicolumn{3}{|l|}{ O-antigen } \\
\hline$d d h A(100 \%, Y e)$ & Glucose-1-phosphate cytidyltransferase & 0.00013 \\
\hline$d d h B(100 \%, Y e)$ & CDP-glucose 4,6-dehydratase & $<0.00011$ \\
\hline wbcC $(100 \%, Y e)$ & Abequosyltransferase & 0.0065 \\
\hline$w b c F(100 \%, Y e)$ & Unknown & $<0.081$ \\
\hline$w b c H(100 \%, Y e)$ & Galactoside 2-L-fucosyltransferase & $<0.000056$ \\
\hline wbcl $(100 \%, Y e)$ & Galactosyltransferase & 0.000078 \\
\hline $\operatorname{manC}(100 \%, \mathrm{Ye})$ & GDP-mannose pyrophosphorylase & $<0.00038$ \\
\hline $\operatorname{man} B(100 \%, Y e)$ & Phosphomannomutase & 0.00011 \\
\hline galE $(100 \%, Y e)$ & UDP-glucose 4-epimerase & $<0.011$ \\
\hline \multicolumn{3}{|c|}{ Miscellaneous chromosomal mutants } \\
\hline yifH $(67 \%, \mathrm{Ec})$ & Enterobacterial common antigen synthesis & 0.07 \\
\hline dnaJ $(79 \%, S t)$ & Heat shock response & 0.0052 \\
\hline pstC $(72 \%, \mathrm{Ec})$ & Inorganic phosphate importer & 0.005 \\
\hline topA $(93 \%, \mathrm{Ec})$ & DNA topoisomerase I & 0.0068 \\
\hline$n / p D(72 \%$, Ec $)$ & Outer membrane lipoprotein & 0.10 \\
\hline$p s p C(62 \%, \mathrm{Ec})$ & Regulation of phage shock protein operon & 0.000041 \\
\hline irp1 $(100 \%, Y e)$ & Siderophore synthesis & 0.017 \\
\hline yibP $(40-55 \%$, Ec) & Unknown & 0.18 \\
\hline$y s p C(100 \%$ Ye $)$ & Ysa type III secretion system effector & 0.36 \\
\hline \multicolumn{3}{|c|}{$\begin{array}{l}\text { a. Amino acid identity (over the region sequenced) compared to the most similar homologue (Ye, Yersinia enterocolitica; Ec, Escherichia coli; St, } \\
\text { Salmonella typhimurium). } \\
\text { b. Mice were infected i.p. with an input ratio of approximately 1:1 (mutant: wild type bacteria). Survivors were recovered from the spleen after } 48 \text { hours, } \\
\text { and the output ratio of mutant to wild type was determined. Competitive index is the output ratio divided by input ratio. A competitive index of less than } \\
\text { one indicates that the mutant is less virulent than the wild type. The lower the competitive index, the more severe is the virulence defect. A number } \\
\text { beginning with "<" indicates that no mutant bacteria were recovered in one or more of the test animals. ND = not determined. In some cases multiple } \\
\text { mutations in the same gene were isolated. In this case, the mutant with the lowest competitive index is shown. }\end{array}$} \\
\hline
\end{tabular}

effect of a ysaV null mutation on virulence following either oral or i.p. infections (Haller et al., 2000). Together, all of these observations support a role for the Ysa type III secretion system in the pathogenesis of a Y. enterocolitica infection.

One of the chromosomal virulence genes identified is homologous to the $p s p C$ gene of $E$. coli. The $Y$. enterocolitica $p s p C$ mutation caused a level of attenuation that was equivalent to that of a virulence plasmid-cured strain. Essentially, the $p s p C$ mutant is completely avirulent as measured by the i.p. infection competition assay. The $Y$. enterocolitica psp locus became the subject of a subsequent study (see below), and continues to be an area of interest in my laboratory.
The Psp system. The E. coli K-12 phage shock protein (psp) locus was discovered because infection with a filamentous phage caused massive production of the PspA protein (Brissette et al., 1990). Subsequent work demonstrated that PspA protein synthesis is induced by the mislocalization of a secretin protein, which is an outer membrane pore-forming protein used by the phage to secrete progeny from the infected cell. Homologous secretins are also essential components of a number of bacterial systems, including type II and type III secretion systems, and type IV pilus biosynthesis. The overproduction of a number of these secretin proteins has been shown to induce E. coli PspA synthesis. The role of the E. coli Psp system is unknown, but it has been hypothesized to be a stress response system that is 
activated by an unknown signal (reviewed by Model et al., 1997; Darwin, 2005).

The $Y$. enterocolitica $p s p C$ null mutant was avirulent in mice, but grew normally in LB broth at $26^{\circ} \mathrm{C}$ (Darwin and Miller, 1999). However, subsequent analysis indicated that the mutant had a growth defect under conditions that induce production of the virulence-plasmid encoded Ysc type III secretion system. Specifically, mislocalization of the YscC secretin protein caused a complete growth arrest of the $p s p C$ mutant (Darwin and Miller, 2001). Therefore, it was concluded that the attenuation of the $p s p C$ mutant was due, at least in part, to stress resulting from mislocalization of the YscC secretin.

This conclusion assumes that a certain proportion of YscC protein does not become correctly localized in the outer membrane during host infection. This has not been directly tested, and it would not be easy to do so. However, it is somewhat reminiscent of the situation involving the assembly of the $\mathrm{P}$ pilus of uropathogenic $E$. coli. In this case, it is proposed that some $P$ pilus subunits become mislocalized. This is sensed by the Cpx extracytoplasmic stress response pathway, which itself can control $P$ pilus biosynthesis (Hung et al., 2001). However, whilst the Psp extracytoplasmic stress response system somehow senses mislocalized YscC protein, there is no evidence that the psp system directly controls biosynthesis of the Ysc type III secretion system itself. In fact, the Y. enterocolitica pspC null mutant still assembles a functional Ysc system, at least in vitro (Darwin and Miller, 2001).

Analysis of the $Y$. enterocolitica Psp system is ongoing in my laboratory, both with respect to its role in virulence, and its role in the physiology of the bacterial cell. We are attempting to understand the nature of the inducing signal (Maxson and Darwin, 2004), whether other virulence factors besides YscC might also be inducers, the molecular details of the signal transduction mechanisms, and to identify genes controlled by the Psp response system (Green and Darwin, 2004).

\section{Y. pseudotuberculosis STM screen (oral infection)}

The results from two Y. pseudotuberculosis STM screens were reported in 2001, both of which studied the same strain (strain YPIII pIB1; Karlyshev et al., 2001; Mecsas et al., 2001). The first of these was able to overcome the "bottleneck" problem reported above, which allowed the oral route of infection to be used (this was achieved by reducing the complexity of the mutant pool to 48 different mutants). In an informative set of preliminary experiments, it was concluded that oral infection with a pool of 48 mutants would allow the identification of those mutants unable to survive in the cecum, and possibly the mesenteric lymph nodes. However, subsequent dissemination to the spleen was too inefficient to allow the identification of attenuated mutants in this tissue (Mecsas et al., 2001).

Another series of preliminary experiments indicated that a strain unable to secrete the Yops was not complemented by the wild type strain in mixed infections. However, this does not rule out the possibility that a defect in only one specific Yop protein might be complemented by the wild type strain. Of course, addressing this question for each of the secreted Yops would be a significant undertaking, beyond the scope of their study. However, it's an interesting question for the future.

The authors of this study also reported that, following oral infection, the Y. pseudotuberculosis Yop-secretion mutant grew less well than the wild type in all tissues, and was most significantly attenuated in the cecum, Peyer's patches and spleen. However, the Yop secretion mutant was occasionally detected in the mesenteric lymph nodes, where the fold enrichment of the wild type over the mutant was occasionally less than 20-fold (Mecsas et al., 2001).

Their preliminary experiments led the authors to conclude that the cecum may be the best selective environment to identify attenuated mutants following orogastric infection. Therefore, a library of $960 \mathrm{Y}$. pseudotuberculosis signature-tagged transposon insertion mutants was generated and screened for reduced virulence following oral infection of BALB/C mice. After a double-screening procedure, similar to that described above for $Y$. enterocolitica, 19 mutants were found that were not detected in the cecum and/or the Peyer's patches and mesenteric lymph nodes. However, only 13 of these 19 mutants had a virulence defect when they were tested individually in separate oral mouse infections. In particular, it was found that mutants that were absent from the Peyer's patches and mesenteric lymph nodes, but present in the cecum in the original screening procedure, were as virulent as wild type when tested individually. Therefore, the authors concluded that their screen was only able to reliably identify mutants defective for survival in the cecum.

DNA sequence analysis of the transposon-insertion sites in the attenuated mutants revealed that 13 different virulence loci had been identified (Table 4). Of these, six were on the virulence plasmid, and seven on the chromosome. Four of the virulence plasmid mutations affected structural components of the Ysc type III secretion system ( $y s c H, y s c U, y s c B$ and $y s c L)$, and these mutants were unable to secrete any of the Yops (Mecsas et al., 2001). One of the virulence plasmid insertions was in the IcrV gene, and this mutant secreted all of the Yops except for LcrV, YopB and YopD. An IcrR mutant was also isolated, but it behaved like the wild type strain in vitro, secreting all Yops under low-calcium conditions, but not under high-calcium conditions. The isolation of these virulence plasmid mutants, and the preliminary experiments with the Yop-secretion mutant, indicate that the Ysc type III secretion system is important for survival in the cecum. More specifically, it suggests that the secretion of one or more secreted Yop proteins plays a role in the cecum, which is an intriguing observation. However, no individual yop insertion mutants were isolated in the screen. This is similar to the $Y$. enterocolitica STM screen, in which only one yop gene mutant was identified amongst many mutations affecting structural components of the Ysc system, or its regulation (Darwin and Miller, 1999).

Three of the chromosomal mutations affected biosynthesis of the O-antigen component of lipopolysaccharide (Table 4). Surprisingly, these mutants were defective in the ability to invade epithelial cells in vitro (Mecsas et al., 2001). In fact, the invasion defect of the O-antigen mutants was similar to that of an invasin- 


\begin{tabular}{|l|l|l|}
\hline \multicolumn{2}{|l|}{ Table 4. Y. pseudotuberculosis virulence genes identified by STM after oral infection and recovery of the bacteria from the cecum. } \\
\hline Encoded protein/homologue a & Function or property & Cecum virulence defect ${ }^{\text {b }}$ \\
\hline Virulence plasmid & Ysc-Yop Type III secretion & ND \\
\hline$y s c H$ & Ysc-Yop Type III secretion & ND \\
\hline$y s c U$ & Ysc-Yop Type III secretion & ND \\
\hline$y s c B$ & Ysc-Yop Type III secretion & ND \\
\hline$y s c L$ & Ysc-Yop Type III secretion & -2.01 \\
\hline IcrR & Ysc-Yop Type III secretion & ND \\
\hline IcrV & \multicolumn{2}{|l|}{} \\
\hline O-antigen & Glucose-1-phosphate cytidyltransferase & ND \\
\hline$d d h C$ & O-antigen flippase & -2.71 \\
\hline wzx & GDP-D-mannose dehydratase & -2.97 \\
\hline gmd & & \\
\hline Miscellaneous chromosomal mutants & Invasin, entry into host cells & -1.63 \\
\hline inv & Unknown function (peptidoglycan biosynthesis?) & ND \\
\hline sufl & Cardiolipin synthesis & -3.42 \\
\hline cls & Ribosomal protein, kasugamycin resistance & -0.59 \\
\hline ksgA & R. For homologous genes, the level of amino acid identity, or the organism with the homologue, was not reported. \\
\hline $\begin{array}{l}\text { b. Mice were infected with an equal mixture of mutant and wild type strains. 5 days later, the numbers of wild type and mutant bacteria in the cecum } \\
\text { was determined. The virulence defect is expressed as: log CFU of mutant - log CFU of wild type. }\end{array}$ \\
\hline
\end{tabular}

defective mutant (inv), which was also isolated in the screen. However, it is clear that this invasion defect is not the only deficiency of the O-antigen mutants, because they were severely attenuated in an i.p. infection, whereas the inv mutant was fully virulent (Mecsas et al., 2001). Furthermore, O-antigen mutants were also isolated in the Y. enterocolitica STM screen, which used an i.p. route of infection (Darwin and Miller, 1999).

The remaining four chromosomal mutations affected inv (described above), and three other genes that had not previously been implicated in virulence ( $k s g A$, sufl and $c / s$ ). None of these latter three mutants were defective in Yop synthesis or delivery, or in the ability to invade cultured epithelial cells in vitro. KsgA is a ribosomal protein that is targeted by the drug kasugamycin. The $k s g A$ mutant had a growth defect under some conditions, which might explain its virulence defect (although, mice shed the $\mathrm{ksgA}$ mutant 40 days postinfection, suggesting that it survives and replicates in the cecum for long periods). The authors also discussed the possibility that the virulence phenotype of the $k s g A$ mutant could be due to polar effects on downstream genes, which are predicted to be involved in metal ion transport.

The sufl and cls mutations are both likely to affect the cell envelope. The E. coli sufl gene was originally identified as a multicopy suppressor of a temperaturesensitive ftsl (PBP-3) mutation. Although the role of sufl has not been studied, it seems likely that it plays a role in peptidoglycan biosynthesis. The $\mathrm{cls}$ gene is predicted to encode cardiolipin synthase, which makes one of the primary phospholipids in the cell envelope.

Finally, the authors of this study made two additional observations worthy of note. First, 12 of the 13 mutants identified as attenuated in the cecum were also defective for growth in the spleen following an i.p. infection. This indicates that these mutants would have been isolated regardless of the route of infection used in the screen. However, there was one exception (the inv mutant), which suggests some benefit to doing STM screens using different routes of infection with the same pathogen-animal system. Second, in their preliminary experiments the authors reported that they occasionally found signaturetagged strains that were present in the spleen, but absent from the mesenteric lymph nodes of the same mouse. It is possible that these strains passed through the mesenteric lymph nodes but did not establish a persistent infection there, or that they were able to infect the spleen without passing through the mesenteric lymph nodes at all. These observations point to the usefulness of signature-tagged strains in studying the dynamics of an animal infection, in addition to their use in identifying attenuated mutants.

\section{Y. pseudotuberculosis STM screen (intravenous infection)}

The authors of the second Y. pseudotuberculosis STM screen made some modifications to the technique (Karlyshev et al., 2001). First, each transposon had two different signature tags, which had been pre-selected on the basis of uniform hybridization efficiency, and lack of cross hybridization. Second, a high-density oligonucleotide array was used for the detection of signature tags, which allowed quantification of the hybridization signals. An intravenous route of infection was used (tail vein injection). A dose 30 to 300 times higher than the $L D_{50}$ was used to avoid any potential bottleneck problem.

A library of 603 signature-tagged transposon insertion mutants was generated and used to infect mice in pools of 30 or 60 different mutants. Surviving bacteria were recovered from the spleen after three days. From this, 31 putative attenuated mutants were identified, which were in 
30 different loci. This is a higher percentage of attenuated mutants than occurred in the other Yersinia STM screens, as well as some of the STM screens in other species. The authors suggested that this might have been the result of their modifications to the STM technique, which allowed quantification of hybridization signals and increased overall reliability due to the double tags. However, it should also be noted that a lower stringency of criteria was used to define attenuation in their study when compared to the other Yersinia STM screens. Of the 31 different mutants, the competitive index of 20 was determined individually. Of these, the authors noted that only 14 had a competitive index of less than 0.3. Of these 14 mutants, two had an in vitro competitive defect that was the same or even more severe than the competitive defect in mice. Therefore, if the criteria used to define attenuation were the same as in the other Yersinia studies (see above), then the percentage of attenuated mutants isolated in this screen would probably be quite similar.

Twenty-seven of the putative virulence loci that were identified in the screen are listed in Table 5. However, as mentioned above, it is not clear if all of these meet the criteria used in the other Yersinia STM screens. The virulence defect of each individual mutant would have to be determined in order to clarify this.

Many of the genes identified are predicted to be involved in lipopolysaccharide biosynthesis, which is consistent with the other Yersinia STM screens. However, unlike the other STM screens, none of the mutations were in the virulence plasmid. As the authors pointed out, this is probably because the transposon mutant library was pre-screened on Congo red magnesium oxalate plates to

\begin{tabular}{|c|c|c|}
\hline Encoded protein/homologue a & Function or property & Competitive index ${ }^{b}$ \\
\hline \multicolumn{3}{|l|}{ LPS biosynthesis } \\
\hline YPO0054, 97\% & Glycosyltransferase & $0.03^{*}$ \\
\hline YPO1382, 97\% & LpsA, glycosyltransferase & $0.08^{*}$ \\
\hline YPO2174, 98\% & UDP-glucose-6-dehydrogensae & ND \\
\hline YPO3099, 96\% & ManC, mannose-1-P guanylyltransferase & $0.43^{*}$ \\
\hline YPO3100, 98\% & Fcl, fucose synthetase & 0.13 \\
\hline YPO3104, 90\% & O-antigen polymerase & 0.29 \\
\hline YPO3114, 98\% & DdhB, CDP-D-glucose-dehydratase & ND \\
\hline YPO3116, 95\% & AscD, ascarylose biosynthesis & 0.04 \\
\hline S. enterica Wzx, $80 \%$ & O-antigen flippase & 0.003 \\
\hline \multicolumn{3}{|c|}{ Miscellaneous chromosomal mutants } \\
\hline YPO0702, 99\% & Putative lipoprotein & ND \\
\hline YPO1108, 98\% & Citrate synthase & $0.48^{*}$ \\
\hline YPO1174, 96\% & Putative adhesin & 0.53 \\
\hline YPO1186, 98\% & Amino acid transport & 0.055 \\
\hline YPO1987, 95\% & Unknown function & 0.021 \\
\hline YPO1994, 97\% & Unknown function & 0.084 \\
\hline YPO2287, 96\% & Amino acid transport & 0.0036 \\
\hline YPO2440, 98\% & Iron transport & 0.25 \\
\hline YPO2532, $100 \%$ & Unknown function & ND \\
\hline YPO2712, 98\% & RseA, negative regulation of $r p o E$ & ND \\
\hline YPO3004, 97\% & Prodipeptidase & 0.27 \\
\hline YPO3144, 97\% & MdIB, mutidrug resistance protein & 0.21 \\
\hline YPO3572, 98\% & Putative transcriptional regulator & 0.44 \\
\hline YPO3657-8, 97\% & Unknown function & ND \\
\hline YPO3834, 99\% & PldA, phospholipase A & 0.017 \\
\hline YPO3965, 96\% & VirA, His kinase & 0.41 \\
\hline Xyella fastidiosa orf, $70 \%$ & Phage-related transcriptional activator & ND \\
\hline Phage HP1 orf, $59 \%$ & Unknown & 0.89 \\
\hline \multicolumn{3}{|c|}{$\begin{array}{l}\text { a. Amino acid identity (over the region sequenced) compared to the most similar homologue. In most cases, this was a Y. pestis CO92 orthologue } \\
\text { (YPO). Where two genes are listed, the transposon insertion was in the intergenic region. Some transposon insertions were in regions with no se- } \\
\text { quence similarity to the databases, and they are omitted from this table. } \\
\text { b. Mice were infected i.v. with an input ratio of approximately 1:1 (mutant: wild type bacteria). Survivors were recovered from the spleen after three } \\
\text { days, and the output ratio of mutant to wild type was determined. Competitive index is the output ratio divided by input ratio. A competitive index of less } \\
\text { than one indicates that the mutant is less virulent than the wild type. The lower the competitive index, the more severe is the virulence defect. ND = } \\
\text { not determined. An asterisk indicates mutants where the in vitro competitive index (not shown) was equal or less than this mouse competitive index. In } \\
\text { cases where more than one mutation in the same gene was isolated, the mutant with the lowest competitive index is shown. }\end{array}$} \\
\hline
\end{tabular}


confirm the presence of the virulence plasmid. Disruption of structural or regulatory components of the Ysc type III secretion system would probably cause an abnormal phenotype on these plates, resulting in their elimination from the mutant library. However, insertions in yop genes would be unlikely to cause an abnormal phenotype on magnesium oxalate plates (for example, a yop $P$ null mutant has a wild type phenotype; see Darwin and Miller, 1999). Therefore, the pre-screening does not explain the fact that individual yop mutants were not identified in this STM screen. However, this result is consistent with the rarity of individual yop mutants in the other Yersinia STM screens.

The other genes identified in the screen are predicted to encode a variety of different functions. These include amino acid and iron transport proteins, transcriptional regulators and a putative adhesin. One of the transposon insertions disrupted the $r s e A$ gene, which encodes a negative regulator of the RpoE sigma factor. The $Y$. enterocolitica rpoE promoter was identified in an IVET screen (Table 1). Together, these observations suggest that modulation of the Yersinia RpoE extracytoplasmic stress response is important during host infection.

A phospholipase gene was also identified in this screen. Phospholipases had been identified as virulence determinants in other bacterial pathogens, but not in $Y$. pseudotuberculosis. Therefore, the authors went on to characterize the phospholipase mutant in more detail, as discussed below.

During the characterization of the transposon insertion sites, the authors noted whether or not there was an orthologue of each gene in Y. pestis (Table 5; Karlyshev et al., 2001). Most of the genes identified did have a $Y$. pestis orthologue. However, there were some exceptions. The authors suggested that these exceptions might contribute to the different tropisms of the closely related $Y$. pseudotuberculosis and $Y$. pestis pathogens, which are predicted to have had a relatively recent common ancestor (Achtman et al., 1999).

PIdA. One of the attenuated mutants had a transposon insertion in a gene encoding a 282 amino acid protein with homology to a family of bacterial outer membrane phospholipases A. The mutant had a mouse competitive index of 0.017 , indicating significant attenuation, and an in vitro competitive index of 0.46 . Furthermore, following i.v. injection the median lethal dose of the mutant was approximately 200-fold higher than that of the wild type strain (Karlyshev et al., 2001). Note that the median lethal dose is the expected median dose required to produce morbidity or death. This is different to the $L D_{50}$, which measures the dose expected to kill $50 \%$ of infected animals.

The pldA mutant was shown to have significantly reduced phospholipase activity (172 units) when compared to the wild type (449 units). The remaining activity was postulated to be due to other phospholipases. Indeed, a non-homologous phospholipase A (YpIA) has been characterized in $Y$. enterocolitica, and implicated in its virulence (Schmiel et al., 1998). PCR analysis indicated that a homologous $y$ plA gene is also present in Y. pseudotuberculosis (Karlyshev et al., 2001), possibly explaining the residual activity of the pldA mutant. In a previous study the $y$ pIA gene was not detected in $Y$. pseudotuberculosis by southern hybridization analysis with a Y. enterocolitica yplA probe (Schmiel et al., 1998). However, this may simply have been due to the level of stringency used in the experiment.

Phospholipases $\mathrm{C}$ are known to be important virulence factors for a number of bacterial pathogens (Titball, 1993). However, the role of phospholipases A in virulence is less well studied, with YpIA of Y. enterocolitica being an exception. The authors postulated that PIdA might mimic the effects of mammalian phospholipases $A$, which release arachidonic acid from host cell membrane phospholipids. The released arachidonic acid can serve as a substrate for the generation of a variety of inflammatory mediators.

It was also postulated that PIdA might play a role in the invasion of host cells, although this was not tested. The authors based this hypothesis on two observations. First, PldA of Helicobacter pylori is essential for the colonization of gastric mucosa (Dorrell et al., 1999). Second, activation of host phospholipase A2 in cultured epithelial cells was required for invasion by $S$. enterica serovar Typhimurium (Pace et al., 1993). Although this involves a host phospholipase $A$, it is possible that the surface-bound PIdA of $Y$. pseudotuberculosis could contribute to this process. This is an interesting hypothesis that will have to be tested in future experiments.

Y. pestis STM screen (subcutaneous infection)

A relatively small scale STM screen was reported for $Y$. pestis (Flashner et al., 2004). In this case a subcutaneous (s.c.) route of infection was used to mimic a natural infection from a flea bite. The $Y$. pestis Kimberley53 strain was used, which was obtained by passage of the Kimberley strain (Ben-Gurion and Hertman, 1958) in mice. The $L_{50}$ of the Kimberley53 strain following subcutaneous infection of mice was as low as $1 \mathrm{CFU}$.

Three hundred $Y$. pestis Kimberley53 signaturetagged transposon insertion mutants, in pools of 20 mutants each, were screened by s.c. infection of female OF1 outbred mice with a total dose of $10^{4}$ CFU. Mice were sacrificed 48 hours post-infection and surviving bacteria were recovered from the spleen. After a tworound screening procedure, similar to those described above, 16 putative attenuated mutants were identified. All of these mutants competed equally with the wild type strain when grown in rich media in vitro. The mutants were divided into four different groups, depending on their virulence properties (Table 6). Some of the mutants had indistinguishable virulence properties from the wild type. However, the authors reported that they were consistently unable to compete in the spleen when administered in a pool of at least 10 different mutants. Therefore, they are included in Table 6.

As with the other Yersinia STM screens, the disrupted genes encode a variety of functions. An apparently striking difference from the other screens is the lack of O-antigen biosynthesis mutants. However, the authors pointed out that a trivial explanation for this is that the O-antigen biosynthesis genes are inactive in $Y$. pestis. Only one 


\begin{tabular}{|c|c|c|}
\hline Encoded protein ${ }^{a}$ & Function or property & Competitive index ${ }^{b}$ \\
\hline \multicolumn{3}{|l|}{ Mouse non-lethal ${ }^{c}$} \\
\hline YPO3728 & PurH, purine biosynthesis & $<10^{-7}$ \\
\hline YPCD1.49 & LcrF, regulator of Yop regulon & $<10^{-7}$ \\
\hline YPO3357 & $\begin{array}{l}\text { Pcm, protein-L-isoaspartate O-methyl transfer- } \\
\text { ase }\end{array}$ & $3 \times 10^{-5}$ \\
\hline \multicolumn{3}{|c|}{ Delayed mouse lethality ${ }^{c}$} \\
\hline YPO3077 & PurK, purine biosynthesis & 0.002 \\
\hline YPO3505 & GreA, Transcription elongation factor & 0.08 \\
\hline \multicolumn{3}{|c|}{ Unchanged mouse lethality $(\mathrm{Cl}<0.3)^{\mathrm{c}}$} \\
\hline YPMT1.89 & DnaE, DNA polymerase III $\alpha$ subunit & 0.035 \\
\hline YPO2027 & Putative sulfate transporter & 0.054 \\
\hline YPO0458-9 & $750 \mathrm{p}$ upstream of thrA (asparatokinase) & 0.057 \\
\hline YPO3045-6 & Between convergently transcribed genes & 0.15 \\
\hline YPO1179 & Putative nuclease & 0.26 \\
\hline \multicolumn{3}{|c|}{ Unchanged mouse lethality $(\mathrm{Cl}>0.3)^{\circ}$} \\
\hline YPO3973 & Putative metalloprotease & 0.52 \\
\hline YPO1994 & Unknown function & 0.56 \\
\hline YPO2793 & Putative membrane protein, unknown function & 0.78 \\
\hline YPO2947 & Unknown function & 1.07 \\
\hline YPO2471 & Putative exported protein, unknown function & 1.54 \\
\hline YPO1003-4 & Upstream of putative autotransporter & 1.87 \\
\hline \multicolumn{3}{|c|}{$\begin{array}{l}\text { a. This Y. pestis CO92 orthologue (YPO) of the Y. pestis Kimberley53 gene is shown. Where two genes are listed, the transposon insertion was in the } \\
\text { intergenic region. } \\
\text { b. Mice were infected subcutaneously with an input ratio of approximately 1:1 (mutant: wild type bacteria). Survivors were recovered from the spleen } \\
\text { after } 48 \text { hours, and the output ratio of mutant to wild type was determined. Competitive index (Cl) is the output ratio divided by input ratio. A competitiv } \\
\text { index of less than one indicates that the mutant is less virulent than the wild type. The lower the competitive index, the more severe is the virulence } \\
\text { defect. ND = not determined. } \\
\text { c. Groups of three mice were infected Mouse non-lethal mutants did not cause death in any of three infected mice subcutaneously with } 100 \mathrm{CFU} \text { of } \\
\text { each mutant, and monitored for } 21 \text { days. All three mice survived for mouse non-lethal mutants, and all three mice died for all other classes. The mean } \\
\text { time to death was longer than for the wild type strain in the case of the delayed mouse lethality strains. }\end{array}$} \\
\hline
\end{tabular}

virulence plasmid mutant was obtained $($ IcrF), but this is probably a reflection of the relatively small mutant library.

With a goal of identifying a possible vaccine strain, the authors focused their attention on a mutant with an insertion in $\mathrm{pcm}$, encoding a protein-L-isoaspartate $\mathrm{O}$ methyl transferase. In E. coli, Pcm is important for survival in a variety of stress conditions ( $\mathrm{Li}$ and Clarke, 1992; Visick et al., 1998). This Y. pestis pcm mutant was unable to kill mice and had a severe competitive defect in the spleen (Flashner et al., 2004). The authors reported that it was superior to the EV76 live vaccine strain, inducing 10- to 100 -fold higher antibody titers to the protective $\mathrm{V}$ and F1 antigens and because it was better at conferring protective immunity.

\section{IVET and STM: comparison and conclusions}

The IVET and STM techniques have now been used to study a number of different pathogens. Therefore, it seems appropriate to consider the question of how the two compare. For this review, I will confine this comparison to the case of $Y$. enterocolitica where both have been used. The most striking observation is the almost complete lack of overlap between the genes identified (compare Tables $1-2$ with Table 3). This is true, even when only comparing the IVET and STM studies in which the i.p. route of infection was used, and bacteria were harvested from the spleen after two days (Tables 2 and 3 ). However, there is one important caveat to this observation. Both of the Y. enterocolitica IVET screens used operon fusion libraries generated from the genomic DNA of a virulence plasmid-cured strain. This was done so that novel virulence genes might be identified, rather than the known virulence plasmid genes. If the virulence plasmid DNA had been included in the library, it seems likely that some of the genes would have been identified in the IVET screens, which would increase the amount of overlap with the STM screen.

Aside from the special case of virulence plasmid genes, why was there so little overlap in the genes identified by the two techniques? One reason is that the techniques ask different questions. The IVET screens were designed to identify genes expressed in the animal, but not in the laboratory. However, some of the genes identified by STM (e.g. the O-antigen biosynthesis genes) are expected to be expressed significantly in the laboratory. Another difference is that IVET identifies promoter fusions, whereas STM identifies null mutants. Therefore, STM cannot identify essential genes. IVET can 
identify this class of genes, provided that their expression in the laboratory is quite low and less than during infection of the host. An example is provided by the rpoE gene, identified by IVET, and later shown to be an essential $Y$. enterocolitica gene (Heusipp et al., 2003). Therefore, it is possible that some of the other genes identified by IVET are also essential, which would explain their absence amongst the genes found by STM. However, it is clear that not all of the IVET genes are essential, and in the cases where null mutants were shown to reduce bacterial load in the host, one would expect these genes to be identified by STM. Of course, there are some technical considerations that may also explain the lack of overlap. For example, mutants that could not grow on minimal media were excluded from the STM screen. The transposon insertion library (STM) and operon fusion libraries (IVET) may not have been completely random, and were certainly not comprehensive. It is possible for some of the IVET operon fusion integrants to be polar within operons that might be required for virulence, preventing the survival of these strains in the animal.

Regardless of the reasons behind the lack of overlap, both IVET and STM have been successful in identifying novel Yersinia virulence genes. Many of the genes identified are involved in metabolic functions, and this is beginning to give us a picture of the physiology of Yersinia cells during host infection. Whilst these may not be socalled "classical virulence factors", their identification and future characterization is of great importance and interest. After all, the most successful antibacterial agents to date are antibiotics, which do not specifically target virulence factors.

Some of the genes identified are known or thought to encode proteins involved in stress responses (e.g. acrA, clpX, dnaJ, pspC and rpoE). This apparently points to the importance of the ability of the infecting organism to respond to the environmental changes encountered in the host, such as changes in temperature, $\mathrm{pH}$ and osmolarity. The RpoE and PspC proteins are apparently involved in separate extracytoplasmic stress responses, which might be triggered by the production of virulence proteins located in the cell envelope, or that must pass through the cell envelope during their secretion. Indeed, induction of the Psp response is triggered by an essential component of the Ysc type III secretion system (Darwin and Miller, 2001), and by other secretin proteins that play a role in virulence (Maxson and Darwin, 2004). It would be interesting to know whether specific virulence proteins also induce the RpoE response of Yersinia species.

The results of the various Yersinia IVET and STM screens also demonstrate the importance of using different methods, and different infection models, to identify virulence genes. With the availability of annotated genome sequence information, the characterization of loci identified by these techniques can proceed much more rapidly than previously. Therefore, we have probably not seen the last of the application of these techniques to the study of Yersinia pathogenesis.

\section{A brief word about subtractive hybridization}

It seems appropriate here to briefly discuss another genome-wide approach that has recently been used to identify Yersinia virulence genes, even though it is not an in vivo technology. This method, known as suppressive subtractive hybridization, was used to identify a novel chromosomal locus that was unique to the a $Y$. enterocolitica serotype 0:8 biotype 1B strain (Iwobi et al., 2003).

Total genomic DNA of a non-pathogenic $Y$. enterocolitica biotype 1A strain was subtracted from the genome of a highly pathogenic $Y$. enterocolitica serotype $\mathrm{O}: 8$ biotype $1 \mathrm{~B}$ strain. The success of the technique was validated by PCR analysis of the resulting clones, which led to the identification of the ail (attachment and invasion locus) and inv (invasin) genes, and also several genes from the high pathogenicity island. Therefore, 200 subtracted clones were analyzed, and they generally fell into three categories: sequences similar to known genes from Yersinia or other species; sequences similar to phages and mobile genetic elements; sequences with no similarity to the databases. The authors focused on one of the sequences that was homologous to the epsE gene of $V$. cholerae, which encodes part of a type II secretion system.

Further analysis indicated that the epsE homologue is part of a cluster of genes (named the yts 1 cluster), which is homologous to loci from various other species that encode type II secretion systems. The system shared the most similarity with the Eps system of $V$. cholerae, which exports a protease, a chitinase, and the most important $V$. cholerae virulence factor, cholera toxin. Southern hybridization analysis of various Yersinia strains confirmed that the Yts1D secretion system is only present in the highly pathogenic $Y$. enterocolitica strains, and is also not found in any other Yersinia species. Interestingly, analysis of the $Y$. enterocolitica strain 8081 genome sequence revealed the presence of another locus encoding a type II secretion system (Yts2). Unlike yts1, the yts2 locus was found to be present in all $Y$. enterocolitica strains tested. However, like yts1, the yts2 locus was not found in $Y$. pestis or Y. pseudotuberculosis.

A yts1E null mutant was shown to be significantly attenuated in a mouse model of oral infection. 48 hours after infection the bacterial CFU recovered from the liver and spleen were approximately 100 -fold lower for the mutant than for the wild type strain. However, the mutant showed only a minor reduction in the CFU recovered from the small intestine and Peyer's patches. Therefore, the Yts1 secretion system appears to be important for later stages of the infection. This could be either the process of dissemination, or the ability to survive in tissues such as the liver and spleen. The authors of this study postulated that the Yts1 secretion system must be responsible for the secretion of one or more virulence factors.

\section{Future prospects}

All future studies intended to identify Yersinia virulence genes should be greatly impacted by the availability of genome sequence information. At the time this review was written, the genome sequences of three $Y$. pestis strains have been published (Parkhill et al., 2001; Deng et al., 2002; Song et al., 2004), as has that of a Y. pseudotuberculosis strain (Chain et al., 2004), and the annotated genome sequence of the highly pathogenic $Y$. 
enterocolitica strain 8081 is available online (http://www. sanger.ac.uk/Projects/Y_enterocolitica/). In terms of locating virulence genes, there will be obvious advances facilitated by the availability of this information. First, it will greatly aid any future IVET and STM studies. Only a few base pairs of DNA sequence information will be required to determine the genomic context of an IVET operon fusion, or STM transposon insertion. Not only will this save time and money, but it also increases the ability to interpret limited data. An example of this is demonstrated by one of the mutants from the $Y$. enterocolitica STM screen. Initial sequence analysis revealed no homology to database entries (Darwin and Miller, 1999). However, the analysis of a much larger contig from the genome revealed that the transposon insertion was in the $y s p C$ gene (see above).

Another advance is that genome sequences provide the ability to use other methods to identify Yersinia virulence genes. For example, microarray studies to identify all members of a virulence regulon, or genes that are specifically expressed under conditions found in the host. Bioinformatics will also become important by allowing the identification of candidate virulence genes based on their homology to known virulence factors from other organisms. In the future, it will also be interesting to determine the genome sequences of multiple strains of the same species that differ in their levels of virulence. An example would be to compare the genome sequences of non-pathogenic, low-level pathogenic, and highly pathogenic $Y$. enterocolitica strains.

The screens described in this review have already told us a great deal about the Yersinia genes that must be expressed during host infection. Genomics holds the promise of extending these conclusions further. Perhaps it is now reasonable to set a somewhat ambitious longterm goal. This would be to have a comprehensive understanding of all genes that must be expressed during infection in an animal model, for all three of the pathogenic Yersinia species. We are already on the way to achieving this goal.

\section{Acknowledgments}

Work in my laboratory is supported by National Institutes of Health grant Al52148, and by a grant from the Speaker's Fund for Biomedical Research: Toward the Science of Patient Care, awarded by the City of New York. I thank Virginia Miller and Glenn Young for their permission to cite unpublished data.

\section{References}

Achtman, M., Zurth, Z., Morelli, G., Torrea, G., Guiyoule, A., and Carniel, E. (1999). Yersinia pestis, the cause of plague, is a recently emerged clone of Yersinia pseudotuberculosis. Proc. Natl. Acad. Sci. USA 96: 14043-14048.

Ben-Gurion, R., and Hertman, I. (1958). Bacteriocinlike material produced by Pasteurella pestis. J. Gen. Microbiol. 19: 289-297.

Brissette, J.L., Russel, M., Weiner, L., and Model, P. (1990). Phage shock protein, a stress protein of Escherichia coli. Proc. Natl. Acad. Sci. USA 87: 862-866.

Carniel, E. (2001). The Yersinia high-pathogenicity island: an iron-uptake island. Microbes. Infect. 3: 561-569.
Chain, P.S., Carniel, E., Larimer, F.W., Lamerdin, J., Stoutland, P.O., Regala, W.M., Georgescu, A.M., Vergez, L.M., Land, M.L., Motin, V.L., Brubaker, R.R., Fowler, J., Hinnebusch, J., Marceau, M., Medigue, C., Simonet, M., Chenal-Francisque, V., Souza, B., Dacheux, D., Elliott, J.M., Derbise, A., Hauser, L.J., and Garcia, E. (2004). Insights into the evolution of Yersinia pestis through whole-genome comparison with Yersinia pseudotuberculosis. Proc. Natl. Acad. Sci. USA 101: 13826-13831.

Chiang, S., and Mekalanos, J. (1998). Use of signaturetagged transposon mutagenesis to identify Vibrio cholerae genes critical for colonization. Mol. Microbiol. 27: 797-805.

Darwin, A.J. (2005). The phage-shock-protein-response. Mol. Microbiol. doi:10.1111/j.1365-2958.2005.04694.x: In press

Darwin, A.J., and Miller, V.L. (1999). Identification of Yersinia enterocolitica genes affecting survival in an animal host using signature-tagged transposon mutagenesis. Mol. Microbiol. 32: 51-62.

Darwin, A.J., and Miller, V.L. (2001). The psp locus of Yersinia enterocolitica is required for virulence and for growth in vitro when the Ysc type III secretion system is produced. Mol. Microbiol. 39: 429-444.

De Las Penas, A., Connolly, L., and Gross, C.A. (1997). $\sigma^{\mathrm{E}}$ is an essential sigma factor in Escherichia coli. J. Bacteriol. 179: 6862-6864.

Deng, W., Burland, V., Plunkett, G., 3rd, Boutin, A., Mayhew, G.F., Liss, P., Perna, N.T., Rose, D.J., Mau, B., Zhou, S., Schwartz, D.C., Fetherston, J.D., Lindler, L.E., Brubaker, R.R., Plano, G.V., Straley, S.C., McDonough, K.A., Nilles, M.L., Matson, J.S., Blattner, F.R., and Perry, R.D. 2002. Genome sequence of Yersinia pestis KIM. J. Bacteriol. 184: 4601-4611.

Dorrell, N., Martino, M.C., Stabler, A., Ward, S.J., Zhang, Z.W., McColm, A.A., Farthing, M.J., and Wren, B.W. (1999). Characterization of Helicobacter pylori PIdA, a phospholipase with a role in colonization of the gastric mucosa. Gastroenterology 117: 1098-1104.

Fernandez, L., Marquez, I., and Guijarro, J.A. (2004). Identification of specific in vivo-induced (ivi) genes in Yersinia ruckeri and analysis of ruckerbactin, a catecholate siderophore iron acquisition system. Appl. Environ. Microbiol. 70: 5199-5207.

Flashner, Y., Mamroud, E., Tidhar, A., Ber, R., Aftalion, M., Gur, D., Lazar, S., Zvi, A., Bino, T., Ariel, N., Velan, B., Shafferman, A., and Cohen, S. (2004). Generation of Yersinia pestis attenuated strains by signature-tagged mutagenesis in search of novel vaccine candidates. Infect. Immun. 72: 908-915.

Foultier, B., Troisfontaines, P., Vertommen, D., Marenne, M.N., Rider, M., Parsot, C., and Cornelis, G.R. (2003). Identification of substrates from the Yersinia enterocolitica 1B Ysa type III secretion system. Infect. Immun. 71: 242-253.

Galloway, S.M., and Raetz, C.R. (1990). A mutant of Escherichia coli defective in the first step of endotoxin biosynthesis. J. Biol. Chem. 265: 6394-6640.

Gort, A.S., and Miller, V.L. (2000). Identification and characterization of Yersinia enterocolitica genes 
induced during systemic infection. Infect. Immun. 68: 6633-6642.

Green, R.C., and Darwin, A.J. (2004). PspG, a new member of the Yersinia enterocolitica phage shock protein regulon. J. Bacteriol. 186: 4910-4920.

Haller, J.C., Carlson, S., Pederson, K.J., and Pierson, D.E. (2000). A chromosomally encoded type III secretion pathway in Yersinia enterocolitica is important in virulence. Mol. Microbiol. 36: 1436-1446.

Handfield, M., and Levesque, R.C. (1999). Strategies for isolation of in vivo expressed genes from bacteria. FEMS Microbiol. Rev. 23: 69-91.

Hensel, M., Shea, J.E., Gleeson, C., Jones, M.D., Dalton, E., and Holden, D.W. (1995). Simultaneous identification of bacterial virulence genes by negative selection. Science 269: 400-403.

Heusipp, G., Schmidt, M.A., and Miller, V.L. (2003). Identification of rpoE and nadB as host responsive elements of Yersinia enterocolitica. FEMS Microbiol. Lett. 226: 291-298.

Heusipp, G., Young, G.M., and Miller, V.L. (2001). HreP, an in vivo-expressed protease of Yersinia enterocolitica, is a new member of the family of subtilisin/kexin-like proteases. J. Bacteriol. 183: 3556-3563.

Hung, D.L., Raivio, T.L., Jones, C.H., Silhavy, T.J., and Hultgren, S.J. (2001). Cpx signaling pathway monitors biogenesis and affects assembly and expression of $P$ pili. EMBO J. 20: 1508-1518.

Iwobi, A., Heesemann, J., Garcia, E., Igwe, E., Noelting, C., and Rakin, A. (2003). Novel virulence-associated type II secretion system unique to high-pathogenicity Yersinia enterocolitca. Infect. Immun. 71: 1872-1879.

Karlyshev, A.V., Oyston, P.C.F., K., W., Clark, G.C., Titball, R.W., Winzeler, E.A., and Wren, B.W. (2001). Application of high-density array-based signaturetagged mutagenesis to discover novel Yersinia virulence-associated genes. Infect. Immun. 69: 7810 7819.

Kelley, T.M., Stachula, S.A., Raetz, C.R.H., and Anderson, M.S. (1993). The firA gene of Escherichia coli encodes UDP-3-(R-3-hydroxymyristol)-glucosamine N-acyltransferase. J. Biol. Chem. 268: 19866-19874.

Kennedy, E. (1996). Membrane-derived oligosaccharides (periplasmic beta-D-glucans) of Escherichia coli. In: Escherichia coli and Salmonella: cellular and molecular biology. F. C. Neidhardt, R. Curtis III, J. L. Ingraham, E. C. C. Lin, K. Brooks Low, B. Magasanik, W. S. Reznikoff, M. Riley, M. Schaechter and H. E. Umbarger, eds. ASM Press, Washington, D.C. p. 1064-1071.

Lesic, B., and Carniel, E. (2004). The high-pathogenicity island: a broad-host-range pathogenicity island. In: Yersinia molecular and cellular biology. E. Carniel and B. J. Hinnebusch, eds. Horizon Bioscience, Wymondham, U.K. p. 285-306.

Li, C., and Clarke, S. (1992). A protein methyltransferase specific for altered aspartyl residues is important in Escherichia coli stationary-phase survival and heatshock resistance. Proc. Natl. Acad. Sci. USA. 89: 9885-9889.

Mahan, M.J., Slauch, J.M., and Mekalanos, J.J. (1993). Selection of bacterial virulence genes that are specifically induced in host tissues. Science 259: 686-688.
Maxson, M.E., and Darwin, A.J. (2004). Identification of inducers of the Yersinia enterocolitica phage shock protein system and comparison to the regulation of the RpoE and Cpx extracytoplasmic stress responses. J. Bacteriol. 186: 4199-4208.

Mecsas, J. (2002). Use of signature-tagged mutagenesis in pathogenesis studies. Curr. Opin. Microbiol. 5: 3337.

Mecsas, J., Bilis, I., and Falkow, S. (2001). Identification of attenuated Yersinia pseudotuberculosis strains and characterization of an orogastric infection in BALB/ C mice on day 5 postinfection by signature-tagged mutagenesis. Infect. Immun. 67: 2779-2787.

Model, P., Jovanovic, G., and Dworkin, J. (1997). The Escherichia coli phage-shock-protein ( $p s p)$ operon. Mol. Microbiol. 24: 255-261.

Morris, V.L., Jackson, D.P., Grattan, M., Ainsworth, T., and Cuppels, D.A. (1995). Isolation and sequence analysis of the Pseudomonas syringae pv. tomato gene encoding a 2,3-diphosphoglycerate-independent phosphoglyceromutase. J. Bacteriol. 177: 1727-1733.

Mukhopadhyay, P., Williams, J., and Mills, D. (1988). Molecular analysis of a pathogenicity locus in Pseudomonas syringae pv. syringae. J. Bacteriol. 170: 5479-5488.

Nelson, K.M., Young, G.M., and Miller, V.L. (2001). Identification of a locus involved in systemic dissemination of Yersinia enterocolitica. Infect. Immun. 69: 6201-6208.

Orth, K. (2002). Function of the Yersinia effector YopJ. Curr. Opin. Microbiol. 5: 38-43.

Pace, J., Hayman, M.J., and Galan, J.E. (1993). Signal transduction and invasion of epithelial cells by $S$. typhimurium. Cell 72: 505-514.

Parkhill, J., Wren, B.W., Thomson, N.R., Titball, R.W., Holden, M.T., Prentice, M.B., Sebaihia, M., James, K.D., Churcher, C., Mungall, K.L., Baker, S., Basham, D., Bentley, S.D., Brooks, K., Cerdeno-Tarraga, A.M., Chillingworth, T., Cronin, A., Davies, R.M., Davis, P., Dougan, G., Feltwell, T., Hamlin, N., Holroyd, S., Jagels, K., Karlyshev, A.V., Leather, S., Moule, S., Oyston, P.C., Quail, M., Rutherford, K., Simmonds, M., Skelton, J., Stevens, K., Whitehead, S., and Barrell, B.G. (2001). Genome sequence of Yersinia pestis, the causative agent of plague. Nature 413: 523-527.

Schmiel, D.H., Wagar, E., Karamanou, L., Weeks, D., and Miller, V.L. (1998). Phospholipase A of Yersinia enterocolitica contributes to pathogenesis in a mouse model. Infect. Immun. 66: 3941-3951.

Song, Y., Tong, Z., Wang, J., Wang, L., Guo, Z., Han, Y., Zhang, J., Pei, D., Zhou, D., Qin, H., Pang, X., Zhai, J., Li, M., Cui, B., Qi, Z., Jin, L., Dai, R., Chen, F., Li, S., Ye, C., Du, Z., Lin, W., Yu, J., Yang, H., Huang, P., and Yang, R. (2004). Complete genome sequence of Yersinia pestis strain 91001, an isolate avirulent to humans. DNA Res. 11: 179-197.

Titball, R.W. (1993). Bacterial phospholipases C. Microbiol. Rev. 57: 347-366.

Visick, J.E., Cai, H., and Clarke, S. (1998). The Lisoaspartyl protein repair methyltransferase enhances survival of aging Escherichia coli subjected to secondary environmental stresses. J. Bacteriol. 180: 2623-2629. 
Vuorio, R., Harkonen, T., Tolvannen, M., and Vaara, M. (1994). The novel hexapeptide motif found in the acetyltransferases $L p x A$ and $L p x D$ of lipid A biosynthesis is conserved in various bacteria. FEBS Lett. 337: 289292.

Vuorio, R., Hirvas, L., and Vaara, M. (1991). The Ssc protein of enteric bacteria has significant homology to the acyltransferases LpxA of lipid A biosynthesis, and to three acetyltransferases. FEBS Lett. 292: 90-94.
Young, G.M., and Miller, V.L. (1997). Identification of novel chromosomal loci affecting Yersinia enterocolitica pathogenesis. Mol. Microbiol. 25: 319-328.

Zhang, L., Radziejewshka-Lebrecht, J., KrajewskaPietrasik, D., Toivanen, P., and Skurnik, M. (1997). Molecular and chemical characterization of lipopolysaccharide O-antigen and its role in the virulence of Yersinia enterocolitica serotype 0:8. Mol. Microbiol. 23: 63-76. 


\section{Further Reading}

Caister Academic Press is a leading academic publisher of advanced texts in microbiology, molecular biology and medical research. Full details of all our publications at caister.com

- MALDI-TOF Mass Spectrometry in Microbiology Edited by: M Kostrzewa, S Schubert (2016) www.caister.com/malditof

- Aspergillus and Penicillium in the Post-genomic Era Edited by: RP Vries, IB Gelber, MR Andersen (2016) www.caister.com/aspergillus2

- The Bacteriocins: Current Knowledge and Future Prospects Edited by: RL Dorit, SM Roy, MA Riley (2016)

www.caister.com/bacteriocins

- Omics in Plant Disease Resistance Edited by: V Bhadauria (2016) www.caister.com/opd

- Acidophiles: Life in Extremely Acidic Environments Edited by: R Quatrini, DB Johnson (2016) www.caister.com/acidophiles

- Climate Change and Microbial Ecology: Current Research and Future Trend

Edited by: J Marxsen (2016)

www.caister.com/climate

- Biofilms in Bioremediation: Current Research and Emerging Technologies

Edited by: G Lear (2016)

www.caister.com/biorem

- Microalgae: Current Research and Applications Edited by: MN Tsaloglou (2016) www.caister.com/microalgae

- Gas Plasma Sterilization in Microbiology: Theory, Applications, Pitfalls and New Perspectives Edited by: H Shintani, A Sakudo (2016) www.caister.com/gasplasma

- Virus Evolution: Current Research and Future Directions Edited by: SC Weaver, M Denison, M Roossinck, et al. (2016) www.caister.com/virusevol

- Arboviruses: Molecular Biology, Evolution and Control Edited by: N Vasilakis, DJ Gubler (2016) www.caister.com/arbo

- Shigella: Molecular and Cellular Biology Edited by: WD Picking, WL Picking (2016) www.caister.com/shigella

-Aquatic Biofilms: Ecology, Water Quality and Wastewater Treatment

Edited by: AM Romaní, H Guasch, MD Balaguer (2016)

www.caister.com/aquaticbiofilms

- Alphaviruses: Current Biology

Edited by: S Mahalingam, L Herrero, B Herring (2016)

www.caister.com/alpha

- Thermophilic Microorganisms

Edited by: F Li (2015)

www.caister.com/thermophile
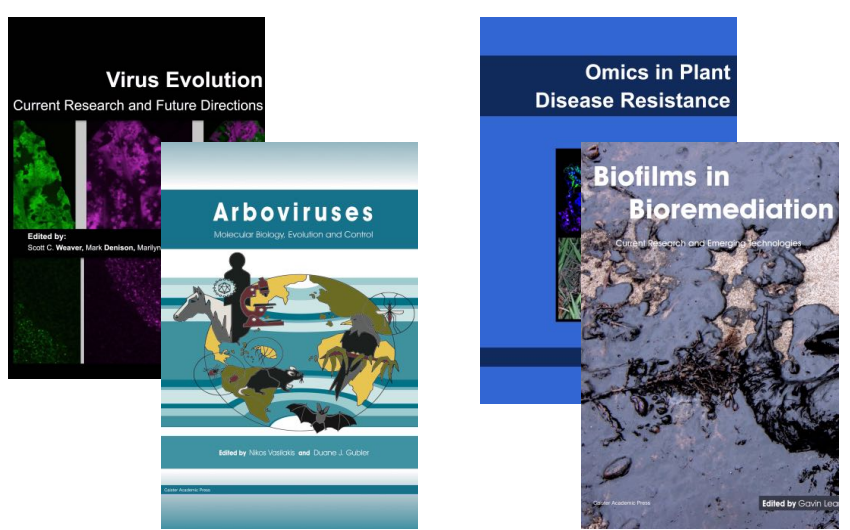
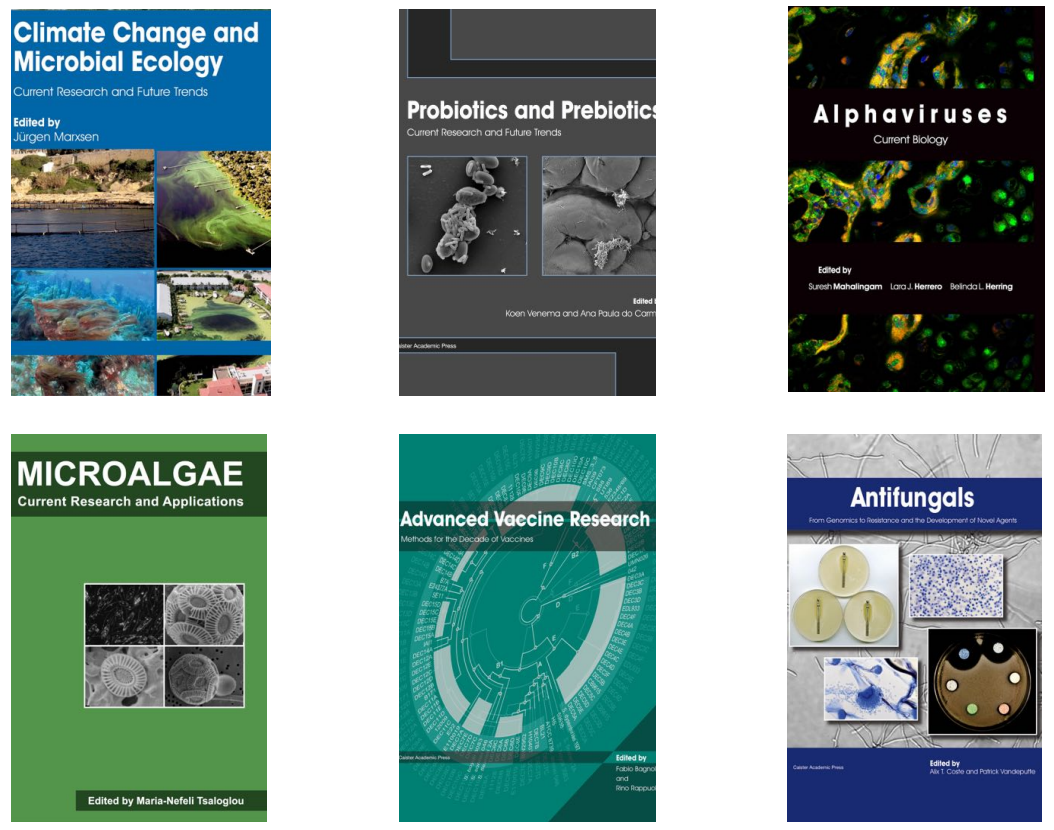

- Flow Cytometry in Microbiology: Technology and Applications Edited by: MG Wilkinson (2015) www.caister.com/flow

- Probiotics and Prebiotics: Current Research and Future Trends Edited by: K Venema, AP Carmo (2015) www.caister.com/probiotics

- Epigenetics: Current Research and Emerging Trends Edited by: BP Chadwick (2015) www.caister.com/epigenetics2015

- Corynebacterium glutamicum: From Systems Biology to Biotechnological Applications

Edited by: A Burkovski (2015)

www.caister.com/cory2

- Advanced Vaccine Research Methods for the Decade of Vaccines

Edited by: F Bagnoli, R Rappuoli (2015)

www.caister.com/vaccines

- Antifungals: From Genomics to Resistance and the Development of Novel Agents

Edited by: AT Coste, P Vandeputte (2015)

www.caister.com/antifungals

- Bacteria-Plant Interactions: Advanced Research and Future Trends Edited by: J Murillo, BA Vinatzer, RW Jackson, et al. (2015) www.caister.com/bacteria-plant

\section{- Aeromonas}

Edited by: J Graf (2015)

www.caister.com/aeromonas

- Antibiotics: Current Innovations and Future Trends

Edited by: S Sánchez, AL Demain (2015)

www.caister.com/antibiotics

- Leishmania: Current Biology and Contro Edited by: S Adak, R Datta (2015) www.caister.com/leish2

- Acanthamoeba: Biology and Pathogenesis (2nd edition) Author: NA Khan (2015)

www.caister.com/acanthamoeba2

- Microarrays: Current Technology, Innovations and Applications Edited by: Z He (2014)

www.caister.com/microarrays2

- Metagenomics of the Microbial Nitrogen Cycle: Theory, Methods and Applications

Edited by: D Marco (2014)

www.caister.com/n2 